\title{
Validity of a novel inertial measurement unit to track barbell velocity
}

\author{
Daniel Varela-Olalla', Dario Álvarez-Salvador², Alejandro Arias-Tomé², Ignacio Collado-Lázaro², Aitor Gamarra-Calavia², \\ Carlos Balsalobre-Fernández ${ }^{1}$ \\ 'Applied Biomechanics and Sports Technology Research Group, department of Physical Education, Sport and Human Movement. Universidad Autónoma de Madrid. Madrid. \\ Spain. ${ }^{2}$ Department of Physical Education, Sport and Human Movement. Universidad Autónoma de Madrid. Madrid. Spain.
}

doi: 10.18176/archmeddeporte.00051

Recibido: $25 / 09 / 2020$

Aceptado: 22/04/2021

Key words:

Resistance training. Movement velocity. Bench press. Monitoring. Technology. Validation

\section{Summary}

The objective of this work is to analyze the reliability and validity of the new inertial measurement unit (IMU) PUSH ${ }^{\mathrm{TM}}$ Band 2.0 to measure barbell velocity. Six healthy males $(24.83 \pm 3.71$ years; $69.88 \pm 8.36 \mathrm{~kg} ; 175.92 \pm 4.5 \mathrm{~cm})$ participated in this study and performed several sets on the bench press. Barbell concentric mean (MV) and peak (PV) velocity were recorded with a LT and the IMU. Pearson correlation coefficient shows a very high relationship for MV ( $r=0.97$; SEE: $0.08 \mathrm{~m} / \mathrm{s} ; 95 \% \mathrm{Cl}: 0.95$ $0.98 ; p<0.001)$ and PV $(r=0.97 ;$ SEE: $0.13 \mathrm{~m} / \mathrm{s} ; 95 \% \mathrm{Cl}: 0.96-0.98 ; p<0.001)$. There was a very high agreement for the values of MV and PV (MV: ICC $=0.945, \mathrm{Cl}=0.834-0.974, \alpha=0.981 ; \mathrm{PV}: \mathrm{ICC}=0.926, \mathrm{Cl}=0.708-0.969, \alpha=0.977)$. Paired sample t-test revealed systematic bias for MV ( $p<0.001$; mean difference between instruments $=0.06 \pm 0.09 \mathrm{~m} / \mathrm{s})$ and $P V(p<0.001$; mean difference between instruments $=0.15 \pm 0.18 \mathrm{~m} / \mathrm{s}$ ). Bland-Altman plots showed almost trivial and moderate relationships for MV $\left(r^{2}=0.1\right)$ and PV $\left(r^{2}=0.37\right)$. In conclusion, the PUSH ${ }^{\mathrm{TM}}$ Band 2.0 was proven to be a valid alternative for measuring barbell velocity in the bench press.
Palabras clave: Entrenamiento de fuerza. Velocidad de ejecución. Press de banca. Monitorización. Tecnología. Validación.

\section{Validación de un nuevo sensor inercial para medir la velocidad de ejecución}

\section{Resumen}

El objetivo de este trabajo es analizar la fiabilidad y validez de la nueva unidad de medición inercial (IMU) PUSH ${ }^{\mathrm{TM}}$ Band 2.0 para medir la velocidad de la barra. Seis hombres sanos (24.83 \pm 3.71 años; $69.88 \pm 8.36$ kg; $175.92 \pm 4.5 \mathrm{~cm}$ ) participaron en este estudio y realizaron varias series en el press de banca. La velocidad concéntrica de barra (MV) y la velocidad pico (PV) se registraron con un LT y la IMU. El coeficiente de correlación de Pearson muestra una relación muy alta para MV $(r=0.97$ SEE: 0.08 m/s; IC 95\%: 0.95-0.98; $p<0.001)$ y PV ( $r=0.97$; SEE: $0.13 \mathrm{~m} / \mathrm{s} ; 95 \%$ IC: 0,96-0,98; $p<0,001)$. Hubo un acuerdo muy alto para los valores de MV y PV (MV: ICC = 0.945, Cl = 0.834-0.974, $\alpha=0.981 ; \mathrm{PV}: \mathrm{ICC}=0.926, \mathrm{Cl}=0.708-0.969, \alpha=0.977)$. La prueba t de muestras relacionadas reveló un sesgo sistemático para MV $(p<0.001$; diferencia media entre instrumentos $=0.06$ $\pm 0.09 \mathrm{~m} / \mathrm{s})$ y PV $(p<0.001$; diferencia media entre instrumentos $=0.15 \pm 0.18 \mathrm{~m} / \mathrm{s})$. Las gráficas de Bland-Altman mostraron relaciones casi triviales y moderadas para VM $\left(r^{2}=0.1\right)$ y VP $\left(r^{2}=0.37\right)$. En conclusión, se demostró que PUSH ${ }^{\top M}$ Band 2.0 es una alternativa válida para medir la velocidad de la barra en el press de banca. 


\section{Introduction}

Accurately controlling and prescribing the training load in resistance training is vital to achieve the desired adaptations'. Specifically, adequate control of intensity has been shown to be a key factor in the improvement of muscular strength ${ }^{2-6}$ which is a determining factor of sports performance ${ }^{3,7,8}$.

Traditionally the intensity of resistance training has been prescribed through percentages of the 1RM (maximum load with which only one repetition can be performed) or through the XRM (maximum number of repetitions that can be performed with a given load) $)^{1,9-11}$. However, in recent years it has been found that movement velocity is the most accurate and safe variable to control and prescribe intensity in resistance training ${ }^{12-14}$ allowing to estimate the 1RM through the load-velocity relationship without performing an RM or XRM test.

To measure the movement velocity there are different instruments such as linear transducers (LT), accelerometers, advanced video analysis systems or mobile applications ${ }^{15-19}$. Linear transducers have been considered as "gold standards", but these devices present two important drawbacks: a) they are relatively expensive for most users; and b) it is necessary to connect the device to the bar with a cable which makes them impractical for daily use. For these reasons, in recent years the reliability and validity of cheaper alternatives such as different models of accelerometers and mobile applications have been proven, several of them demonstrating being valid for measuring barbell velocity ${ }^{15-17}$.

Actually, new alternatives are being presented to measure barbell velocity and different brands try to improve the performance of their products. We hypothesize that the new models of inertial measurement units (IMUs) PUSH ${ }^{\mathrm{TM}}$ Band 2.0 should offer better results than previous models, and being a better alternative to LT. For this reason the objective of this work is to analyze the reliability and validity of the new IMU PUSH ${ }^{\mathrm{TM}}$ Band 2.0 for measuring barbell velocity in the bench press exercise. We hypothesize that this device will have greater results in terms of validity than previous IMUs.

\section{Material and method}

\section{Participants}

Six healthy males $(24.83 \pm 3.71$ years; $69.88 \pm 8.36 \mathrm{~kg} ; 175.92 \pm 4.5 \mathrm{~cm}$; RM $80.83 \pm 21.13 \mathrm{~kg} ;$ VRM $0.17 \pm 0.04 \mathrm{~m} / \mathrm{s}$ ) selected incidentally took part in this study, all of them had at least 1 year of experience in resistance training and in particular in the bench press exercise. None of the participants had physical limitations, health problems or injuries at the time of the test. None of the participants were taking drugs, medications or other substances that could alter their physical performance. Written informed consent was obtained from each participant; the study protocol was approved by the ethics committee at the institutional review board and complied with the Declaration of Helsinki for Human Experimentation.

\section{Procedures}

Participants performed several sets on the bench press exercise starting with a load of $20 \mathrm{~kg}$ and progressively increasing the weight by $10 \mathrm{~kg}$ until a velocity $\approx 0,3 \mathrm{~m} / \mathrm{s}$ was reached, then one last set was performed with an increase of weight of only $5 \mathrm{~kg}$ (if participants did not feel capable of performing this last series they were allowed to finish the protocol in the previous series), therefore, they do not performed the same number of reps. Barbell mean velocity was being recorded with the Smartcoach Power Encoder (Smartcoach Europe, Stockholm, Sweden) LT and the PUSH ${ }^{\mathrm{TM}}$ Band 2.0 IMU (PUSH Inc., Toronto, Canada). Each subject performed 2 sets of 3 repetitions with 20,30 and $40 \mathrm{~kg}$ loads, and then performed 2 sets of 2 repetitions with the $50 \mathrm{~kg}$ load and 2 sets of 1 repetition with the remaining loads. A total of 140 repetitions were performed and 13 repetitions were discarded because the LT could not measure them correctly. Finally a total of 127 repetitions were analyzed. Concentric mean (MV) and peak velocities (PV) of the resultant 127 repetitions measured with both instruments were compared for reliability and validity purposes. Before the data acquisition anthropometric measurements were taken from all subjects using a digital stadiometer with scale (SECA 220, SECA, Germany).

\section{Incremental bench press test}

The warm-up consisted of 5 minutes of joint mobility and 3 sets of 10, 8 and 5 repetitions ( 2 minutes of rest between sets) with loads of 20,30 , and $40 \mathrm{~kg}$ respectively. The initial load of the test was established in $20 \mathrm{~kg}$ and increments of $10 \mathrm{~kg}$ were made until reaching a MV $\approx 0.3 \mathrm{~m} / \mathrm{s}$, then the load was increased $5 \mathrm{~kg}$ for one last set or the test was stopped if the subjects did not feel capable of continuing the test. Subjects performed 2 sets of 3 repetitions with loads form 20 to $40 \mathrm{~kg}$ and 2 sets of 2 repetitions with the $50 \mathrm{~kg}$ load, for the remaining loads (>50 kg) each subject performed 2 sets of 1 repetition. Rest between set was 3 minutes except for the last increment of $5 \mathrm{~kg}$ for which the rest was 5 minutes. The test was carried out in a Smith machine. The subjects were placed in the supine position on a flat bench, with the feet fully supported on the floor and with the hands placed on the bar with a self-selected grip-width. The placement on the bench was adjusted so that the vertical projection of the bar corresponded with the intermammary line of each subject. Subjects were required to perform a pause of $\approx 1$ to 1,5 s between the eccentric and concentric phases when the bar contacted their chest with the purpose of minimizing the effect of the stretch-shortening cycle (SSC) and the contribution of elastic energy to the movement to increase the reliability of the measures ${ }^{20}$. The subjects were instructed to perform the concentric phase at the maximum possible velocity in each repetition.

\section{Instruments}

Linear transducer: The Smartcoach Power Encoder LT (Smartcoach Europe, Stockholm, Sweden) was used as the "gold standard"for measuring barbell mean velocity. The Smartcoach LT cable was attached to the barbell following the criteria described by the manufacturer (the cable needs to be aligned with the vertical axis). Then, the LT was connected to the Smartcoach software 5.3.3.6 installed on a personal computer running the Windows 10 operating system. Mean velocity values in $\mathrm{m} \cdot \mathrm{s}^{-1}$ were recorded for each repetition in the aforementioned software. The LT had a sampling frequency of $1000 \mathrm{~Hz}$. 
Inertial Sensor: The the PUSH ${ }^{\mathrm{TM}}$ Band $2.0 \mathrm{IMU}$ (PUSH Inc., Toronto, Canada) was attached to the barbell by means of the manufacturer Velcro cover following manufacturer criteria. IS was linked to an IOS PUSH App v. 4.1.2 via Bluetooth connection. Mean velocity values in $m$ - $s$-1 were recorded for each repetition in the aforementioned App. The PUSH ${ }^{\mathrm{TM}}$ Band 2.0 consists of a 3-D accelerometer and a 3-D gyroscope that provides 6 degrees of freedom with a sampling rate of $1000 \mathrm{~Hz}$.

\section{Statistical analysis}

Concurrent validity of the IMU was tested using Pearson's productmoment correlation coefficient ( $\mathrm{r}$ ) with 95\% confident intervals (CI) via bootstrapping ( $n=1000)$. To analyze the level of agreement (reliability) between the IMU and the LT, the intraclass correlation coefficient (ICC 2.1) with $95 \% \mathrm{Cl}$ and Cronbach's alpha were used. In addition, Paired sample t-test and Bland-Altman plots were used to identify potential systematic bias by reporting mean bias, standard deviations and the analysis of the regression line of the Bland-Altman plots. The criteria for interpreting the magnitude of the $r$ coefficients were: trivial (0.00-0.09), small (0.10-0.29), moderate (0.30-0.49), large (0.50-0.69), very large (0.70-0.89), nearly perfect (0.90-0.99) and perfect (1.00) $)^{21}$. Level of significance was set at 0.05 and all the analysis were performed using IBM ${ }^{\circledast}$ SPSS ${ }^{\circledR}$ Statistics 23.0 software (SPSS, Chicago, IL).

\section{Results}

\section{Concurrent validity}

Pearson product-moment correlation coefficient showed a significant, very high relationship between the values obtained for MV $(r=0.97$; SEE: $0.08 \mathrm{~m} / \mathrm{s} ; 95 \% \mathrm{Cl}: 0.95-0.98 ; p<0.001)$ and PV $(r=0.97$; SEE: $0.13 \mathrm{~m} / \mathrm{s} ; 95 \% \mathrm{Cl}: 0.96-0.98 ; \mathrm{p}<0.001)$ measured with the IMU and the LT (Figure 1).

\section{Reliability of the measurements with the IS compared to the LT}

There was a very high agreement between the values of MV and PV measured with the IMU and those measured with the LT as revealed by the ICC, Cronbach's alpha and Bland-Altman plots (MV: ICC $=0.945, \mathrm{Cl}$ $=0.834-0.974, \alpha=0.981 ; \mathrm{PV}: \mathrm{ICC}=0.926, \mathrm{Cl}=0.708-0.969, \alpha=0.977)$.

Paired sample t-test revealed systematic bias for MV $(p<0.001$; mean difference between instruments $=0.06 \pm 0.09 \mathrm{~m} / \mathrm{s}$ ) and PV $(p<0.001$; mean difference between instruments $=0.15 \pm 0.18 \mathrm{~m} / \mathrm{s}$ ). When analyzing the Bland-Altman plots a small, almost trivial relationship was observed for MV $\left(r^{2}=0.1\right)$, while PV has shown a moderate relationship $\left(r^{2}=0.37\right)$ (Figure 2$)$.

\section{Discussion}

The PUSH ${ }^{\mathrm{TM}}$ Band $2.0 \mathrm{IMU}$ was found to be reliable and valid for measuring MV and PV in comparison with a LT. Pearson product-moment correlation coefficient showed a very high relationship between values obtained with both instrument for MV $(r=0.97)$ and $P V(r=0.97)$ with
Figure 1. Concurrent validity between both instruments for a) mean velocity and b) peak velocity.

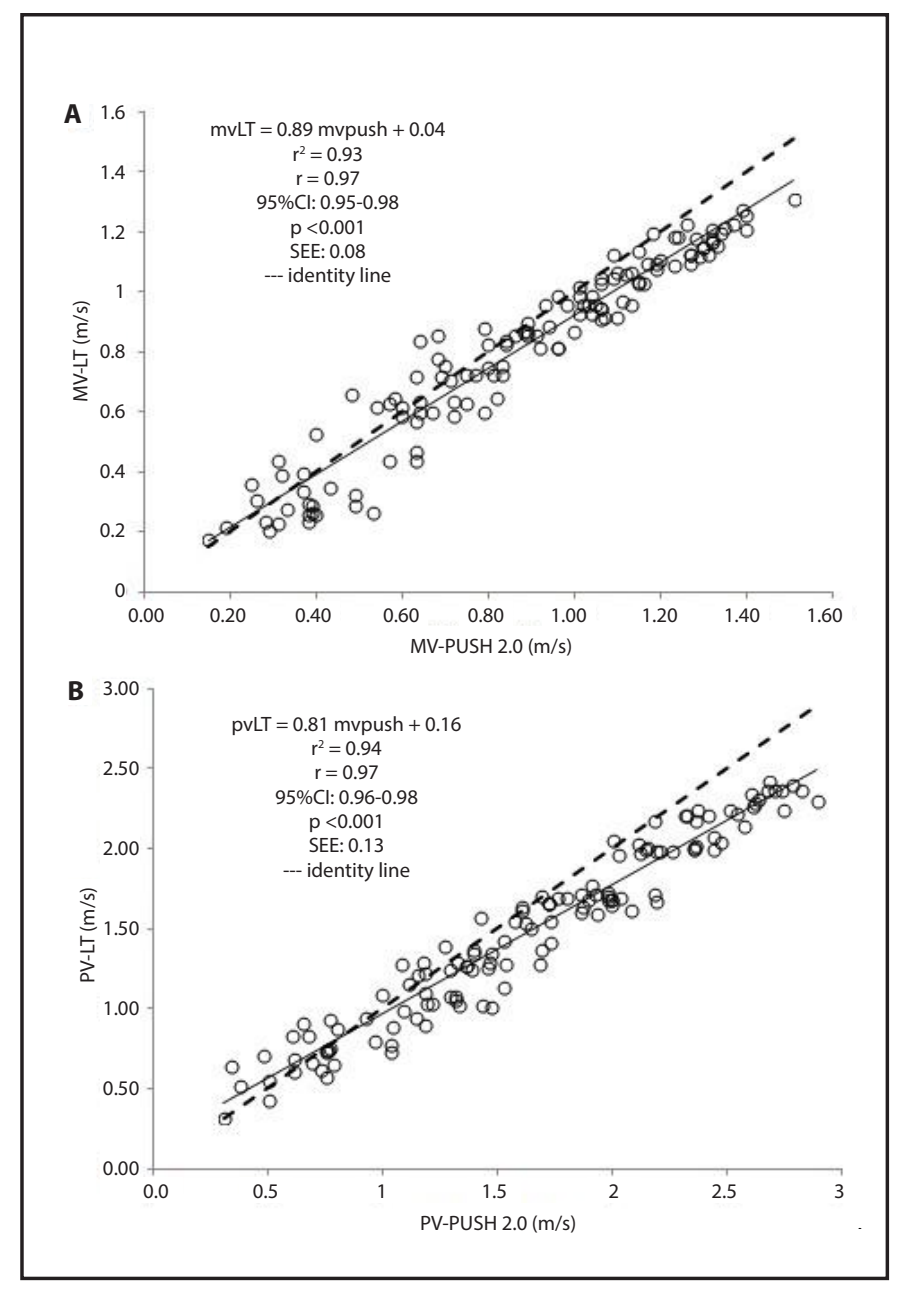

LT: linear transducer; MV: mean velocity; PV: peak velocity.

very narrow Cl via bootstrapping analysis (MV: 0.95-0.98; PV: 0.96-0.98). These results highlight the good association between the instrument for the measurement of MV and PV. In addition, slopes of the regression lines (Figure 1) for MV ( $s=0.89)$ and PV(s=0.81) were very close to identity line $(y=x)$ indicating that values obtained with both devices were very similar. However, paired sample t-test revealed systematic bias between the two instruments by which values of the IMU tended to be higher than those of the LT for the MV and PV (see results for more detail). Finally, the ICC analysis and the Bland-Altman plots revealed a very high level of agreement between the IMU and the LT for MV and a very acceptable to high level of agreement for PV (see results for more detail).

Our results indicate that the PUSH ${ }^{\mathrm{TM}}$ Band 2.0 is a valid option to measure barbell velocity and are in line with previous studies which have shown that different inertial sensors can be used as cheaper and more practical alternatives to $\mathrm{LT}^{15,16}$. Its worth to note that the PUSH ${ }^{\mathrm{TM}}$ Band 2.0 tend to present slightly higher values for MV and PV compared to the LT in accordance with results obtained in the validation of the 
Figure 2. Bland-Altman plots for the measurements of a) mean velocity and b) peak velocity. Horizontal thin lines represent the observed bias $(95 \% \mathrm{Cl})$, while the thick line is the regression line of the data points.

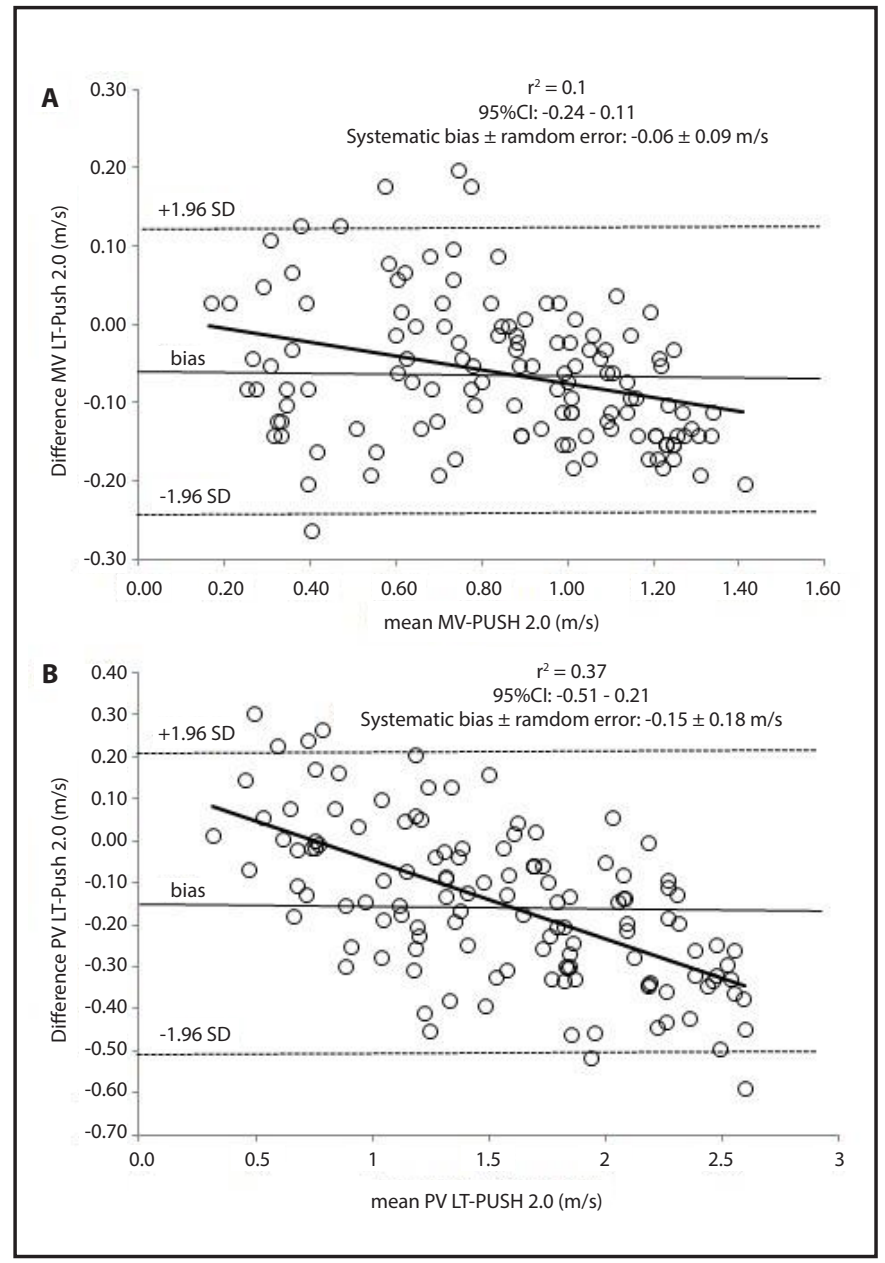

$\mathrm{MV}$ : mean velocity; PV: peak velocity.

Beast sensor IMU ${ }^{15}$. Interestingly, the previous version of the PUSH ${ }^{\mathrm{TM}}$ Band display values slightly lower compared with a LT for PV and slightly higher for $\mathrm{MV}^{16}$. These differences between studies could be in part due to the fact that different LT were used, the different sample frequency of both versions of the PUSH ${ }^{\mathrm{TM}}$ Band (version 1 use a $200 \mathrm{~Hz}$ sample frequency and version 2.0 a $1000 \mathrm{~Hz}$ sample frequency), the different place of attachment of the devices (version 1 has to be attached bellow the elbow of the subject and not directly to the barbell like version 2.0), or all the above. Another important point is that the back squat exercise was used for the validation of the first PUSH ${ }^{\mathrm{TM}}$ Band version while for the present study the bench press exercise was performed.

Despite the methodological differences between studies, it seems clear that PUSH ${ }^{\mathrm{TM}}$ Band 2.0 supposes and improvement in the accuracy of wearable devices for measuring barbell velocity compared to its previous version. In the study of Balsalobre-Fernández et al. ${ }^{16}$ the level of association between PUSH ${ }^{\mathrm{TM}}$ Band and LT was lower than in the present validation of PUSH ${ }^{\mathrm{TM}}$ Band 2.0 for MV $(r=0.86$, SEE: $0.08 \mathrm{~m} / \mathrm{s}$ vs $r=0.97$, SEE: $0.08 \mathrm{~m} / \mathrm{s})$ and PV $(r=0.91$, SEE: $0.1 \mathrm{~m} / \mathrm{s}$ vs $r=0.97$, SEE: $0.13 \mathrm{~m} / \mathrm{s}$ ), our results also show better agreement between $\mathrm{PUSH}^{\mathrm{TM}}$ Band 2.0 and LT (MV ICC: 0.945; PV ICC: 0.926) than the values presented in the study of Balsalobre-Fernández et al. ${ }^{2}$ (MV ICC: 0.907; PV ICC: 0.944). Relative to the validation of the Beast sensor ${ }^{15}$, both devices have showed a similar degree of validity for the bench press exercise when placed directly to the barbell $(r \approx 0.97)$ for MV, however Beast sensor showed lower SEE compared to PUSH TM Band $2.0(0.05 \mathrm{~m} / \mathrm{s}$ vs $0.08 \mathrm{~m} / \mathrm{s})$ and better ICC (0.981 vs 0.945) which could be explained by: 1) differences in the experience and training background of the subjects tested (competitive powerlifters vs healthy active males); and 2) the fact that Balsalobre-Fernández et al..$^{15}$ tested the IMU in a free weight movement while in our study we used a smith machine and this may have affect the values obtained with the LT which is designed to measure only in the vertical axis.

It's worth to note that recently two studies ${ }^{22,23}$ have examined the accuracy and validity of the first PUSH ${ }^{\mathrm{TM}}$ Band version and the Beast sensor. One study showed high concurrent validity for first PUSH ${ }^{\mathrm{TM}}$ Band but not for the Beast sensor ${ }^{23}$, and the other found substantial errors for the validity of the first PUSH ${ }^{\mathrm{TM}}$ Band to measure barbell velocity ${ }^{22}$

One recent study ${ }^{24}$ has analyzed the validity of PUSH ${ }^{\mathrm{TM}}$ Band 2.0 for MV and PV in the free weight bench press exercise. Contrary to our results, Lake et al. ${ }^{24}$ show a better prediction precision of PV than MV, and found proportional bias for the latter. Consistent with our results, this study also found that PUSH ${ }^{\mathrm{TM}}$ Band 2.0 tends to overestimate the bar velocity values highlighting the need to be cautious when comparing data obtained with this device against pre-established load-velocity profiles measured with different instruments. The differences may be due to the fact that Lake et al. ${ }^{24}$ used an optoelectronic 3D motion analysis system as a criterion method, while in our work a LT has been used, and the fact of implementing different statistical methods for data analysis. Furthermore, Lake et al..$^{24}$ analyzed the free weight bench press while in our study it was analyzed on a Smith machine. Finally, Lake et al. ${ }^{24}$ analyze the standard bench press while in our study the subjects were instructed to pause between the eccentric and concentric phases to minimize the effect of SSC, which has been shown to increase the reliability of measurements for $\mathrm{MV}^{20}$. The contradictions exposed indicate the need for further research regarding the validity of this device.

\section{Conclusions}

In conclusion, the PUSH ${ }^{\mathrm{TM}}$ Band 2.0 was proven to be valid and accurate for measuring barbell velocity, especially for MV. However, systematic bias was observed so values obtained with the IMU should not be used as interchangeable with those of a LT. The PUSH ${ }^{\mathrm{TM}}$ Band 2.0 is an affordable and practical system that has been demonstrated to be reliable and valid in comparison with a LT for tracking movement velocity in the bench press exercise. Thus, the PUSH ${ }^{\mathrm{TM}}$ Band 2.0 can be used to monitor and control movement velocity accurately. These results have great practical application for practitioners or strength and conditioning coaches who want to implement velocity-based resistance training and are seeking for accurate alternatives to LT with lower cost. 


\section{Study limitations}

The major drawbacks of the present study are, in first place, the use of mean velocity for the whole range of velocities ranging from loads $<40 \%$ RM to $>90 \%$ RM, since previous studies has shown that mean propulsive velocity (MPV) is more accurate and sensitive for light loads ${ }^{25}$. For that reason it could be recommended to use the PUSH ${ }^{\mathrm{TM}}$ Band 2.0 for measuring loads above $70 \%$ RM as has been recommended for the use of other instruments that only provide values of MV ${ }^{17}$. Secondly, another drawback is that only the bench press exercise was tested and the results obtained should be interpreted with caution for monitoring other exercises.

\section{Future lines of research}

Due to the limitation that only bench press exercise has been analyzed in the present study, and that there are some controversies between the three studies (including the present one) that have investigated the validity of the PUSH ${ }^{\mathrm{TM}}$ Band 2.0; our analyses should be replicated using different exercises performed with and without pause between eccentric and concentric phases, and performed using different materials like smith machines or free weights.

\section{Conflict of interest}

The authors do not declare a conflict of interest.

\section{Bibliography}

1. Kraemer W, and Ratamess N. Fundamentals of resistance training: progression and exercise prescription. Med Sci Sports Exerc. 2004;36:674-88.

2. Campos G, Luecke T, Wendeln H, Toma K, Hagerman F, Murray T, et al. Muscular adaptations in response to three different resistance-training regimens: specificity of repetition maximum training zones. Eur J Appl Physiol. 2002;88:50-60.

3. Folland J, and Williams A. The adaptations to strength training. Sports Med. 2007:37: 145-68.

4. Fry AC. The role of resistance exercise intensity on muscle fibre adaptations. Sports Med. 2004;34:663-79.

5. Heggelund J, Fimland M, Helgerud J, and Hoff J. Maximal strength training improves work economy, rate of force development and maximal strength more than conventional strength training. Eur J Appl Physiol. 2013;113:1565-73.

6. Schoenfeld B, Wilson J, Lowery R, and Krieger J. Muscular adaptations in low- versus high-load resistance training: A meta-analysis. Eur J Sport Sci. 2014;16:1-10.

7. Balshaw T, Massey G, Maden-Wilkinson T, Morales-Artacho A, McKeown A, Appleby C, and Folland J. Changes in agonist neural drive, hypertrophy and pre-training strength all contribute to the individual strength gains after resistance training. Euro J Appl Physiol. 2017;117:631-40.

8. SuchomelT, Nimphius S, and Stone M. The importance of muscular strength in athletic performance. Sports Med. 2016;46:1419-49.

9. Dohoney P, Chromiak J, Lemire D, Abadie B, and Kovacs C. Prediction of one repetition maximum (1-rm) strength from a 4-6 RM and a 7-10 RM submaximal strength test in healthy young adult males. J Exerc Physiol Online. 2002;5:54-9.

10. McMaster D, Gill N, Cronin J, and McGuigan M. A brief review of strength and ballistic assessment methodologies in sport. Sports Med. 2014:44:603-23.

11. Reynolds J, Gordon T, and Robergs R. Prediction of one repetition maximum strength from multiple repetition maximum testing and anthropometry. J Strength Cond Res. 2006;20: 584-92

12. González-Badillo JJ, and Sánchez-Medina L. Movement velocity as a measure of loading intensity in resistance training. Int J Sports Med. 2010;31:347-52.

13. Jidovtseff B, Harris NK, Crielaard JM, and Cronin JB. Using the load-velocity relationship for 1RM prediction. J Strength Cond Res. 2011;25:267-70

14. Picerno P, lannetta D, Comotto S, Donati M, Pecoraro F, Zok M, et al. 1RM prediction: a novel methodology based on the force-velocity and load-velocity relationships. Eur J Appl Physiol. 2016;116:2035-43

15. Balsalobre-Fernández C, Marchante D, Baz-Valle E, Alonso-Molero I, Jiménez S, and Muñóz-López M. Analysis of wearable and smartphone-based technologies for the measurement of barbell velocity in different resistance training exercises. Front Physiol. 2017:8:649-58.

16. Balsalobre-Fernández C, Kuzdub M, Poveda-Ortiz P, and Campo-Vecino J. Validity and reliability of the push wearable device to measure movement velocity during the back squat exercise. J Strength Cond Res. 2016:30:1968-74.

17. Balsalobre-Fernández C, Marchante D, Muñoz-López M, and Jiménez S. Validity and reliability of a novel iPhone app for the measurement of barbell velocity and 1 RM on the bench-press exercise. J Sports Sci. 2018;36:64-70.

18. Bardella P, Carrasquilla García I, Pozzo M, Tous-Fajardo J, Saez de Villareal E, and Suarez Arrones L. Optimal sampling frequency in recording of resistance training exercises. Sports Biomech. 2016:16:102-14.

19. Harris N, Cronin J, Taylor K, Boris J, and Sheppard J. Understanding position transducer technology for strength and conditioning practitioners. Strength Cond J. 2010;32: 66-79.

20. Pallarés J, Sánchez-Medina L, Pérez C, De La Cruz-Sánchez E, and Mora-Rodriguez R. Imposing a pause between the eccentric and concentric phases increases the reliability of isoinertial strength assessments. J Sports Sci. 2014;32:1165-75

21. Hopkins WG, Marshall SW, Batterham AM, and Hanin J. Progressive statistics for studies in sports medicine and exercise science. Med Sci Sports Exerc. 2009;41:3-13.

22. Courel-Ibáñez J, Matínez-Cava A, Morán-Navarro R, Escribano-Peñas P, ChavarrenCabrero J, González-Badillo JJ, and Pallarés JG. reproductibility and repeatability of five different technologies for bar velocity measurement in resistance training. Ann Biomed Eng. 2019;47:1523-38.

23. Pérez-Castilla A, Piepoli A, Delgado-García G, Garrido-Blanca G, and García-Ramos A Reliability and concurrent validity of seven commercially available devices for the assessment of movement velocity at different intensities during the bench press. $J$ Strength Cond Res. 2019;33:1258-65.

24. Lake J, Augustus S, Austin K, Comfort P, McMahon J, Mundy P, Haff GG. The reliability and validity of the bar-mounted PUSH BandTM 2.0 during bench press with moderate and heavy loads. J Sports Sci. 2019

25. Sánchez-Medina L, Pérez CE, and González-Badillo JJ. Importance of the propulsive phase in strength assessment. Int J Sports Med. 2010:31:123-9. 